\section{CONGENITAL MALARIA IN ENGLAND}

\section{BY}

S. B. DIMSON, M.D., M.R.C.P.

Paediatrician to Sydenham Children's, East Ham Memorial, London Jewish, and Queen Mary's (Stratford) Hospitals

There is now general agreement that the foetus can become infected by the transmission of malaria parasites across the placenta, although such an event is acknowledged to be very uncommon. It is particularly rare in native populations living in hyperendemic regions, where the incidence of congenital malaria is $0.03 \%$ against $1-4 \%$ in infants born to European mothers (Covell, 1950). An even higher percentage was recorded by Jones (1950), who found three cases of congenital falciparum (malignant tertian) malaria among 37 consecutive deliveries of non-African women at Lagos. Similar series have been reported from Albania and Italy. In Northern Europe, however, cases have been very scanty, and have usually arisen as a result of mothers with malaria coming home from the Tropics to have their babies. Only two cases were discovered in Belgium, both due to vivax (benign tertian) malaria ; the first by Rodhain (1933) in a 9-weeks-old baby and the second by Glorieux (1952) in an infant 7 weeks old.

Three of the four cases so far described in this country were caused by Plasmodium vivax, the diagnosis being made at 16 days (Jones and Brown, 1924), 34 days (Gammie, 1944), and 50 days (Tanner and Hewlett, 1935) after birth. The one case of falciparum malaria was diagnosed at the age of 7 weeks by Moffat (1907).

The case of congenital malaria described below is the second to be reported in this country due to $P$. falciparum, and was diagnosed on the eighth day after birth.

\section{Case Report}

An Englishwoman aged 24 was first seen in the antenatal clinic of Queen Mary's Hospital, Stratford, London, when she was five months pregnant with her second child (the first was born uneventfully at Huddersfield). She gave her London address on registration, but, giving her history, omitted to mention she had come from Lagos, Nigeria, and that she had contracted her first attack of malaria one week before returning to this country by sea, with two possible mild relapses soon after her arrival here.

At her first examination her temperature was $99.4^{\circ} \mathrm{F}$. $\left(37.4^{\circ}\right.$ C.), pulse 98 , and haemoglobin $68 \%$ (10.6 g.). Her blood pressure and urine were normal ; Wassermann reaction and rhesus $(\mathrm{Rh})$ factor negative. Her $\mathrm{Hb}$ averaged 60 to $65 \%$ throughout her pregnancy in spite of oral and intravenous iron, folic acid, and vitamin $B_{12}$. Agglutinins to D-antigen were consistently absent. Five weeks before delivery her $\mathrm{Hb}$ was $60 \%(8.9$ g.), red cells $2,870,000$ per c.mm., white cells 8,100 (polymorphs $73 \%$, lymphocytes $23 \%$, monocytes $3 \%$, eosinophils $1 \%$ ).

After a first stage lasting 4 hours 50 minutes, she was admitted on November 13,1952, in the second stage of labour, which lasted only seven minutes. She was passing a lot of liquor amnii heavily stained with meconium, and the foetal heart sounds were not heard. The baby, which was full-term, was delivered under gas-and-air analgesia. The placenta, battledore in type and weighing $1 \mathrm{lb}$. $7 \frac{3}{4} \mathrm{oz}$. $(0.68 \mathrm{~kg}$.), was delivered 13 minutes later and found to be ragged and infarcted with ragged and ? incomplete membranes. At the end of labour the mother's temperature was $97.6^{\circ} \mathrm{F}$. $\left(36.4^{\circ} \mathrm{C}\right.$.), pulse 76 , respiration 18 , and blood pressure $110 / 70$.

The infant, a female weighing $6 \mathrm{lb} .11 \frac{1}{2} \mathrm{oz}$ ( $(3.05 \mathrm{~kg}$.), was very blue at birth; but cried after two minutes. The cord blood was $\mathrm{Rh}$ positive and the Coombs test was negative.
The temperature of the baby taken routinely soon after birth was $96.6^{\circ}$ F. $\left(35.9^{\circ}\right.$ C.).

Opinions differed on when jaundice first appeared; one house officer and a midwife thought a "few hours" after birth, while another house officer and a second midwife were certain it was present 30 hours after delivery, when the baby attracted attention to itself by a twitching of the lips, chin, and hands. Unfortunately the temperature was not taken at this juncture, and it is therefore impossible to decide in retrospect whether this twitching was caused by cerebral irritation due to precipitate labour and asphyxia neonatorum, or whether it was caused by a paroxysm of fever. When I first saw this baby, 44 hours after birth, the jaundice was intense and of the colour one associates with icterus gravis. The head was retracted without bulging of the anterior fontanelle, the liver was one fingerbreadth and the spleen two fingerbreadths enlarged below the costal margin, urine dark, temperature $100^{\circ} \mathrm{F}$. $\left(37.8^{\circ} \mathrm{C}\right.$.), and respirations 55 . Vomiting occurred after some feeds. The $\mathrm{Hb}$ was $110 \%$ $(16.3 \mathrm{~g}$.

The diagnosis was in doubt, but it was felt that congenital infective hepatitis was a possibility. Examination of the mother's blood, which showed a thymol turbidity of 6 units and colloidal gold of 4 units, seemed to confirm this clinical impression.

Fourth Day (November 16).--Jaundice and head retraction were still very marked, with, in addition, moderate dehydration. The temperature was $102^{\circ} \mathrm{F}$. $\left(38.9^{\circ} \mathrm{C}\right.$.) and respirations 88. The serum thymol turbidity was 3 units and blood culture was sterile. The cerebrospinal fluid was also sterile, but blood-stained, containing 27,000 red cells and 111 white cells per c.mm., of which 44 were polymorphs and 64 were lymphocytes. The urine contained epithelial cells and bilirubin crystals with a trace of albumin : Fouchet's test for bile pigments was strongly positive and Hay's test for bile salts was negative. In view of the serious condition of the baby, aureomycin, $250 \mathrm{mg}$. every six hours, was given by mouth, together with vitamin $K$ and methionine ; subcutaneous $\mathrm{N} / 2$ saline was also given.

Fifth Day.-The maximum temperature recorded was $102.8^{\circ}$ F. $\left(39.3^{\circ}\right.$ C.) and respirations 56. There was no change in the infant's condition.

Sixth Day.-The liver was three fingerbreadths and the spleen two fingerbreadths enlarged. Jaundice and head retraction were unchanged, but the maximum temperature was only $99.8^{\circ} \mathrm{F}$. $\left(37.7^{\circ} \mathrm{C}\right.$.) and respirations 46 . The cerebrospinal fluid now contained 4,600 red cells and 52 white cells per c.mm. (47 polymorphs, 5 lymphocytes). This was the third day on aureomycin and slight improvement only had been made.

Eighth Day.-A chance remark by the ward sister to the effect that the baby was a precious one, since the mother had come all the way from Africa to have it, made one think immediately of congenital malaria. The infant's thin blood film was negative, but the thick drop preparation showed scanty $P$. falciparum (malignant tertian) rings, while the mother's blood films, both thick and thin, showed the same species of parasite but in greater numbers. The baby's white cell count was 21,000 per c.mm. (polymorphs $50 \%$, lymphocytes $37 \%$, monocytes $11 \%$, and metamyelocytes $2 \%$ ) ; dark pigment granules were present in some of the monocytes. The haemoglobin was $90 \%$ (13.3 g.).

Although the infant was by now apyrexial, its condition was unsatisfactory. Jaundice was still intense, head retraction marked, and hepato-splenomegaly pronounced. Aureomycin was stopped as soon as malaria was diagnosed, and mepacrine, $\frac{1}{2}$ tablet $(0.05 \mathrm{~g}$.), was given three times a day. Four doses in all were given, but vomiting was excessive, and it was felt that little was being absorbed. Pyrimethamine ("daraprim ") was therefore obtained.

Tenth Day.-Pyrimethamine, $\frac{1}{4}$ tablet $(6 \mathrm{mg}$.), was given by mouth and repeated on the following day. The baby vomited twice on the first day, but not at all on the next day. The head retraction thereafter was no longer noticeable and the jaundice began to lessen, with the liver now 
two fingerbreadths and the spleen one and a half fingerbreadths enlarged. The urine contained very few bilirubin crystals and no methaemoglobin or urobilinogen, but Fouchet's test was still strongly positive. Schumm's test for methaemalbuminaemia was negative, the van den Bergh reaction direct positive, icterus index approximately 50 units, and thymol turbidity 2 units. The thick drop preparation became negative for malaria parasites from the time antimalarial therapy was instituted.

Fourteenth Day.-The haemoglobin was only $64 \%$ $(9.47$ g.), and therefore iron and vitamin $C$ were prescribed. The infant's general condition was greatly improved despite continuing jaundice and biliuria. The liver was only one and a half fingerbreadths and the spleen one fingerbreadth enlarged.

Eighteenth Day.-The mother, who had meanwhile been successfully treated with mepacrine and proguanil, was able to take her infant home to Huddersfield, albeit still mildly jaundiced but weighing $6 \mathrm{lb} .3 \frac{1}{2} \mathrm{oz}$. $(2.84 \mathrm{~kg}$.) and gaining weight on the breast.

Later Progress. - The baby was readmitted to hospital on January 10,1953 , when $8 \frac{1}{2}$ weeks old, because, while away from London, she had been lethargic for at least a week and very slow in taking the breast, although fed every three hours. There had been a cough for five days before admission. On examination she was cachectic, with an earthy complexion and dry skin, and was alarmingly underweight, weighing only $5 \mathrm{lb}$. $11 \frac{1}{2} \mathrm{oz} .(2.6 \mathrm{~kg}$.). The lungs were full of crepitations, but the temperature and respiration rate were normal. $X$-ray examination showed the appearances of patchy collapse at both bases. Jaundice was absent, but the liver was two fingerbreadths and the spleen one fingerbreadth enlarged below the costal margin. The $\mathrm{Hb}$ was $86 \%(12.73$ g.) and white cells 20,000 per c.mm. ( $77 \%$ polymorphs). No parasites were seen in either the thick or the thin films. The urine contained no bile salts or pigment and the total serum bilirubin was $0.9 \mathrm{mg}$. per $100 \mathrm{ml}$. In spite of the negative blood films a malarial relapse was considered possible, and pyrimethamine was again given ( $\frac{1}{4}$ tablet daily for two days), together with oxygen, penicillin, and aureomycin. It is of interest to note that four days after admission there was an eosinophilia (of $12 \%$ ), which McGregor and Smith (1952) have recorded after the administration of pyrimethamine, and the $\mathrm{Hb}$ at the same time was only $69 \%$ (9.6 g.). Weight gain was rapid, and on discharge from hospital, on February 7 , at the age of $12 \frac{1}{2}$ weeks the infant weighed $7 \frac{1}{2} \mathrm{lb}$. $(3.4 \mathrm{~kg}$.), her spleen was only just palpable, and the liver no longer felt.

A month later the mother returned with her baby to Apapa, near Lagos, where she had resided for a year.

\section{Diagnosis}

Before it was known that the mother had come from Lagos, the newborn infant was suspected of suffering from congenital infective hepatitis, and this diagnosis seemed to be confirmed by the mother's liver-function tests. The vital information that the mother had become pregnant in West Africa was not revealed until the baby was 8 days old. The correct diagnosis then became clear, because war experience in the Tropics has shown how often malarial jaundice can be confused with infective hepatitis until a blood examination for parasites has been made.

The features of jaundice, head retraction, and dyspnoea do not necessarily make the case one of cerebral malaria, because (1) head retraction could well be attributed to cerebral irritation following asphyxia neonatorum and precipitate labour, although it disappeared after pyrimethamine was given; (2) the pleocytosis of the second sample of cerebrospinal fluid could have been due to traumatic haemorrhage when the first sample was taken; and (3) cerebral symptoms often occur in malaria of the young and therefore cerebral malaria is very difficult to diagnose (Williams, 1940). The intense dyspnoea of the infant at the outset is of interest, as, although emphasized in small children by Jemma (1936) and Bergeret (1948), it has been ignored in case reports of congenital malaria. It is of some importance, since differentiation from pneumonia may not be easy.

Whereas diagnosis in the neonatal period is not difficult once malaria has been called to mind, the clinical picture presented a few weeks or months later is quite different. The baby is then anaemic and dehydrated, with an earthy complexion, slate-grey cyanosis, cold extremities, oedema, basal rales, and failure to thrive. The liver and spleen are usually enlarged, but jaundice is rare; fever is sometimes high, but is more often absent, or the temperature is subnormal. This description is strikingly similar to the infant's condition when it was admitted to hospital at the age of $8 \frac{1}{2}$ weeks. There was neither fever nor dyspnoea, and the general appearance, earthy dry skin, and pallor were out of proportion to the signs in the chest. Although a malarial relapse appeared likely, no parasites were found in the blood, and so, although treatment with pyrimethamine and antibiotics was successful, the diagnosis must remain unestablished.

\section{Treatment}

When the original diagnosis of infective hepatitis was made, aureomycin was given on empirical grounds, and it is probable that, as a result, the infant's life was prolonged sufficiently for it to be saved by the antimalarial treatment subsequently given.

Aureomycin has been found to be therapeutically active against plasmodium infections in animals, but in human experiments its action was found to be too delayed to be of value as a curative agent (Cooper et al., 1949). Nevertheless, Ruiz-Sanchez et al. (1951) claimed good results clinically, but found cure was slower than with routine antimalarial drugs. In our case, over the four days aureomycin was given, fever and dyspnoea slowly subsided, and just before mepacrine was substituted scanty falciparum parasites were found in the thick-drop film, confirming the definite but poor therapeutic action of aureomycin.

Mepacrine was not given by intramuscular injection, because of the alarming fits and even deaths recorded in infants and small children by Bruce-Chwatt and Bruce-Chwatt (1950), Jones (1950), and Dockeray.(1951). It was administered orally in a dosage of $50 \mathrm{mg}$. thrice daily, but vomiting was too frequent. It is possible that the dose should not have exceeded $50 \mathrm{mg}$. a day. Reports of pyrimethamine were at that time so encouraging that after only four doses of mepacrine this drug was substituted.

Pyrimethamine had been reported effective in treating falciparum infections in Lagos school-children by Archibald (1951) even when as little as $5 \mathrm{mg}$. was given, but BruceChwatt and Archibald (1953) found that single 25-mg. tablets were more effective in quickly abolishing falciparum parasitaemia. The use of a quarter of a $25-\mathrm{mg}$. tablet on two successive days produced no vomiting on the second day, and only twice on the first day, at times unrelated to the ingestion of the drug. No vomiting occurred when the second course was given $7 \frac{1}{2}$ weeks later. This is a tribute to its non-toxicity, which has been remarked upon by many who have used it-for example, Avery Jones (1952), who found it successful and without ill effects in seven infants aged between 3 and 12 months who were suffering from heavy falciparum malaria and who were given single doses of 5 to $10 \mathrm{mg}$. each. On the other hand, Goodwin (1952) has reported slight gastro-intestinal disturbance in two individuals, while Schmidt and Genther (1953) have struck a warning note as a result of experiments on monkeys which indicate that the drug may constitute a potential hazard to the human user. Some recent reports tend to show that pyrimethamine is not as effective a curative agent in malaria as some of the older established remedies. Further work is still required to establish its precise place in antimalarial therapeutics.

\section{Summary}

A case of congenital falciparum (malignant tertian) malaria is described which, by virtue of the intense jaundice, hepato-splenomegaly, and head retraction 
produced, was thought at first to be due to infective hepatitis. The correct diagnosis became apparent when, on the eighth day after birth, it was learnt that the mother, an Englishwoman, had come home during her pregnancy from Lagos, Nigeria.

It is considered that aureomycin, given before the case was correctly diagnosed, kept the infant alive until more active antimalarial treatment could be adopted.

Mepacrine was given only a short trial, to be followed by pyrimethamine, which proved successful and nontoxic in the dose given. It is possible, but unproved, that 50 days later there was a malarial relapse.

The antimalarial actions of aureomycin and pyrimethamine as curative agents are briefly discussed.

My thanks are due to Dr. M. S. Ross for his pathological investigations, to Mr. B. G. Spiers for allowing me to have access to the antenatal and labour notes, and to Dr. A. C. Doyne Bell for his kind co-operation.

\section{REFERENCES}

Archibald, H. M. (1951). British Medical Journal, 2, 821.

Bergeret, Ch. (1948). Bull méd. Afr. occid. franc., 5, 281.

Bruce-Cnwatt, L. J., and Archibald, H. M. (1953). British Medical Journal, 1, 539.

- and Bruce-Chwatt, J. M. (1950). Ibid., 2, 7

Cooper, W. C., Coatney, G. R., Imboden, C. A., and Jeffery, G. M. (1949) Proc. Soc exp. Biol., N.Y., 72, 587.

Covell, G. (1950). Trop. Dis. Bull., 47, 1147

Dockeray, G. C. (1951). Trans, roy. Soc. trop. Med. Hyg., 45, 275.

Gammie, R. P. (1944). Lancet, 2, 375

Glorieux. E. (1952). Acta paediat. belg., 6, 129.

Goodwin, L. G. (1952). British Medical Journal, 1, 732

Jemma, R. (1936). Brux. méd., 16, 1756.

Jones, B. S. (1950). British Medical Journal, 2, 439.

ones, J. L., and Brown, H. C. (1924). Lancet, 2, 1058

Trans, roy. Soc. trop. Med. Hyg. 46, 564.

McGregor. I. A., and Smith, D. A. (1952). British Medical Journal, 1 730.

Moffat, P. U. (1907). Ibid. 1, 1054

Rodhain, J. (1933). Ann. Soc. belge Méd. trop., 13, 421

Ruiz-Sanchez, F., Nieves, M., Quezada, M., Paredes, M., and Riebeling. R. (1951). Med. Riv. Mex., 31, 183.

Schmidt, L. H., and Genther, C. S. (1953) J. Pharmacol, 107, 61.

Tanner, N. C. and Hewlett R. F. L. (1935). Lancet, 2, 369.

Williams, C. D. (1940). Ibid., 1, 441.

\section{THE VALUE OF RADIOLOGY IN ANTE- PARTUM HAEMORRHAGE}

\author{
BY \\ JOHN DAWSON, M.D., F.F.R., D.M.R. \\ Consultant Radiologist \\ AND

\section{P. R. MITCHELL, M.B., M.R.C.O.G. Consultant Obstetrician} \\ Royal Hampshire County Hospital, Winchester
}

Location of the placental site by plain radiography was first described by Snow and Powell (1934), and later amplified by Dippel and Brown (1940) and Bishop (1945) in the U.S.A. ; but the method had not had an adequate trial in Great Britain until Reid (1949) and Stallworthy (1951) gave an account of how radiological location of the placenta had been applied to the management of ante-partum haemorrhage.

This paper describes the results obtained in the use of radiography in determining the placental site in cases of ante-partum haemorrhage admitted to the Royal Hampshire County Hospital during 1951-3, and how these results have been applied.

\section{Radiological Technique}

The radiological technique follows closely that described by Reid (1949) and Whitehead (1953a); but special filters have not been used and the radiographs were taken on standard equipment supplied to all $x$-ray departments in general hospitals.

When it is decided that the patient is fit for the examination, she empties her bladder and rectum in the ward, and the following views are taken in the $x$-ray department : (1) lateral views of the abdomen in the recumbent position : one penetrated film for the posterior half of the abdomen, and a "soft" film for the anterior half ; $(2)$ a lateral view of the pelvis in the erect or semi-erect position. In a large proportion of cases these two views are sufficient to demonstrate the placental site, since it is usually on the anterior or posterior wall; but when the placenta is entirely or mainly on the lateral wall two additional views are required: (3) antero-posterior or postero-anterior films of the abdomen in the erect position; and (4) oblique films of the abdomen in the recumbent position.

\section{Interpretation of the Radiographs}

(a) Normal Implantation of Placenta.-A placenta implanted in the upper uterine segment can be seen in the lateral radiographs of the abdomen by tracing the uterine and foetal outlines, and noting where an apparent thickening occurs between the two outlines. This "placental shadow" varies in thickness between 3.1 and $5.8 \mathrm{~cm}$.- the remainder of the uterine wall shadow being between 0.5 and $1.3 \mathrm{~cm}$. (Whitehead, 1953a)-and can be seen with definition after the thirty-second week of pregnancy, when subcutaneous fat is deposited in the foetus. There is no constant relation between the dorsal and ventral aspects of the foetus and the placenta. If the placenta cannot be seen on the anterior or posterior wall or fundus, then it is either in the pelvis (placenta praevia) or implanted on the lateral uterine wall, in which case the oblique and postero-anterior views will be required. Normal implantation on the lateral wall is rare, and no such case has occurred in this series. When the placenta is calcified and normally implanted on the anterior wall its outline can be accurately demonstrated (Dawson, 1953).

(b) Placenta Praevia.-If there is placenta praevia, either the " placental shadow" cannot be seen in the upper uterine segment on the lateral and oblique radiographs of the abdomen or, more usually, the "placental shadow" disappears into the pelvis and there is an associated displacement of the foetal skull or other presenting part to be seen in the erect lateral film of the pelvis. The presenting part usually fits symmetrically into the pelvic brim when the placenta is normally implanted, and is displaced by a lowlying placenta. But displacement of the presenting part alone is inadequate for the diagnosis of placenta praevia, since this may be due to many other causes-for example, full bladder and rectum (these should have been excluded before the $x$-ray examination), pelvic tumour, disproportion, short umbilical cord. It is therefore necessary to correlate the "placental shadow" seen in the recumbent lateral films of the abdomen with the displacement of the presenting part seen in the erect film of the pelvis.

Interpretation of the radiographs tends to be difficult and less certain in the following circumstances :

Before the Thirty-second Week of Pregnancy.-In a premature foetus before the thirty-second week, the subcutaneous fat is insufficient to reveal its outline, and the foetal skull is small in relation to the pelvic brim. Antepartum haemorrhage is rarely serious before the thirtysecond week, and in most patients it is possible to repeat the examination at the thirty-fourth or thirty-sixth week, when a more definite opinion can be given.

Abnormal Presentations. - These are a common complication of ante-partum haemorrhage and placenta praevia in particular. In this series there were 4 abnormal presentations in 20 cases of placenta praevia, and 3 abnormal lies in 24 cases of ante-partum haemorrhage with a normally implanted placenta. If possible, the examination should be repeated after version. 